\title{
Fabrication of Cationic Exchange Polystyrene Nanofibers for Drug Delivery
}

\section{Todsapon Nitanan, Prasert Akkaramongkolporn, Theerasak Rojanarata, Tanasait Ngawhirunpat and Praneet Opanasopit*}

Pharmaceutical Development of Green Innovations Group (PDGIG), Faculty of Pharmacy, Silpakorn University, Nakhon Pathom, Thailand.

*For correspondence: Email: praneet@su.ac.th; Tel: +66-34-255800; Fax: +66-34-250941

\begin{abstract}
Purpose: To prepare polystyrene nanofiber ion exchangers (PSNIE) with surface cation exchange functionality using a new method based on electrospinning and also to optimize crosslinking and sulfonation reactions to obtain PSNIE with maximum ion exchange capacity (IEC).

Method: The nanofibers were prepared from $15 \% \mathrm{w} / \mathrm{v}$ polystyrene solution in dimethylacetamide (DMAc) containing $0.025 \% \mathrm{w} / \mathrm{v}$ tetrabutylammonium bromide (TBAB) using electrospinning technique, followed by crosslinking with sulfuric acid/formaldehyde in a ratio ranging from 100/0 to $50 / 50 \mathrm{v} / \mathrm{v}$ and sulfonation in sulfuric acid. Degree of crosslinking was determined as the amount of fibers that remained in dichloromethane. The morphology and diameter of the fibers were evaluated by scanning electron microscopy (SEM) while IEC of PSNIE was performed by salt splitting titration.

Results: PSNIE crosslinked with a sulfuric acid/formaldehyde ratio of $90 / 10$ with $0.1 \% \mathrm{w} / \mathrm{v}$ silver sulfate for $10 \mathrm{~min}$ at $70{ }^{\circ} \mathrm{C}$ and sulfonated in $98 \%$ sulfuric acid with $0.2 \% \mathrm{w} / \mathrm{v}$ silver sulfate as the catalyst at $100{ }^{\circ} \mathrm{C}$ for $30 \mathrm{~min}$ showed a maximum IEC of $3.21 \mathrm{meq} / \mathrm{g}$-dry-PSNIE. Increase in sulfonation temperature caused the IEC of PSNIE to increase due to faster sulfonation. It was observed that the higher the temperature the faster the rate of sulfonation reaction. The diameter of the fibers after sulfonation was $404 \pm 42 \mathrm{~nm}$.

Conclusion: These results indicate that PSNIE can be successfully prepared by electrospinning. Furthermore, cationic drug can be loaded onto the novel PSNIE for controlled release delivery.
\end{abstract}

Keywords: Polystyrene, Ion exchange capacity, Nanofibers, Ion exchangers, Crosslinking, Sulfonation.

Tropical Journal of Pharmaceutical Research is indexed by Science Citation Index (SciSearch), Scopus, International Pharmaceutical Abstract, Chemical Abstracts, Embase, Index Copernicus, EBSCO, African Index Medicus, JournalSeek, Journal Citation Reports/Science Edition, Directory of Open Access Journals (DOAJ), African Journal Online, Bioline International, Open-J-Gate and Pharmacy Abstracts

\section{INTRODUCTION}

Ion exchange membranes and resins are applied widely in various fields such as fractionation of metal in water, food and beverages, stationary phase in column chromatography etc, whereas, in pharmaceutical systems, ion exchange resins are extensively studied in drug delivery systems [1] leading to commercialization of some resinbased formulations, e.g., cholestyramine [2] and Kayexalate $^{\circledR}$ [3]. Recently, increasing attention has been focused on ion exchange fibers due to their advantage over ion exchange resins such as more rapid and efficient ion-exchange performance, more efficient drug loading and release into/from ion exchange fibers, easier incorporation of large-sized molecules and better control of loading/release [4,5]. There are only a few studies that report the pharmaceutical uses of ion-exchange fibers such as gastromucoadhesive delivery system [6] and transdermal delivery system $[7,8]$. 
Many polymers are used to produce nanofibers by electrospinning. Polystyrene (PS) is one of polymers used to produce cation exchange fibers [9]. PS nanofibers were successfully produced using the electrospinning method and it has been demonstrated that electrospun PS nanofibers have interesting applications in many areas [10-12]. The morphology of the PS nanofibers plays an important role in the physical/mechanical properties of the final products to be used in certain applications. Therefore, reproducible electrospinning of uniform PS nanofibers is essential. Recently, we successfully prepared PS nanofibers by optimizing the parameters in the electrospinning process, which included the PS concentration, ratio of the solvent mixture, inner diameter of the capillary tip and the addition of tetrabutylammonium bromide (TBAB) in the solvent mixture [13]. Sulfonation is required to produce cation exchange PS nanofibers [9]. However, the sulfonation of PS nanofibers cannot be successfully performed because PS nanofibers dissolve during the sulfonation reaction. Therefore, crosslinking PS nanofibers prior to sulfonation is required. Furthermore, it is necessary to identify the optimal conditions for the crosslinking and sulfonation of the PS nanofibers to yield water insoluble PSNIE products with an acceptable ion exchange capacity (IEC). The crosslinking reaction of polymers was performed with various methods such as temperature, radiation, and external reactants. The resultant polymers have various types of crosslinkages, such as covalent bonds, ionic bonds and physical crosslinking (Van der Waals and hydrogen bonds), which depends on the type of polymers and crosslinking agents [14]. Therefore, the aim of this study was to prepare polystyrene nanofiber ion exchangers (PSNIE) with surface cation exchange functionality using a new method based on electrospinning, and also to optimize crosslinking and sulfonation reactions to obtain PSNIE with maximum ion exchange capacity (IEC).

\section{EXPERIMENTAL}

\section{Materials}

The polystyrene resin $\left(\mathrm{Mw}=2.99 \times 10^{5} \mathrm{Da}, \mathrm{Mn}=\right.$ $\left.1.19 \times 10^{5} \mathrm{Da}, 685 \mathrm{D}\right)$ was obtained from Dow Plastics, USA. Tetrabutylammonium bromide (TBAB) was purchased from Bio Basic Inc., Canada. Dimethylacetamide (DMAc, $\geq 99.5 \%$ ), silver sulfate, sodium chloride and sodium hydroxide were purchased from the SigmaAldrich Chemical Company, USA. Concentrated sulfuric acid (98\%) was purchased from Mallinckrodt Baker Inc, USA. Formaldehyde 40 $\%$ w/v was obtained from Carlo Erda Reagents.
All of the solvents were of analytical research grade and used without further purification.

\section{Preparation of PSNIE}

\section{Electrospinning process}

PS nanofibers were prepared using our previously described method [11]. Briefly, a 15\% w/v PS solution was prepared by dissolving PS in DMAc with the addition of $0.025 \% \mathrm{w} / \mathrm{v}$ TBAB. The PS solution was contained in a glass syringe with a flat-tip, stainless-steel needle with an inner diameter of $0.5 \mathrm{~mm}$. The applied voltage and the distance between the tip and the collector were fixed at $15 \mathrm{kV}$ and $15 \mathrm{~cm}$, respectively. The feeding rate of the PS solution was $0.4 \mathrm{ml} / \mathrm{h}$ and controlled using a syringe pump (Model:NE-300, New Era Pump Systems Inc.). Finally, the PS nanofibers were collected on aluminum foil that covered the rotating collector.

\section{Crosslinking and sulfonation}

PS nanofibers were cut into small patches $(2 \times 2$ $\mathrm{cm}^{2}$ ) and then immersed in a mixture of $98 \%$ sulfuric acid and formaldehyde (the crosslinking agent) at volume ratios of 100/0, 95/5, 90/10, $85 / 15,80 / 20$ and $50 / 50$. The reaction was performed with and without the addition of silver sulfate (the catalyst) and stirred for 5 to $75 \mathrm{~min}$ at $70 \pm 0.5{ }^{\circ} \mathrm{C}$. Finally, the crosslinked PS fibers were rinsed with a stepped, increasingly dilute solutions of sulfuric acid until pure deionized water was used, then the samples were dried. Prior to sulfonation, the crosslinked PS fibers were swollen in dichloromethane. The crosslinked PS fibers were immersed in $98 \%$ sulfuric acid with and without the addition of silver sulfate as catalyst $(0-1 \% \quad \mathrm{w} / \mathrm{v})$ at temperatures ranging from 50 to $100{ }^{\circ} \mathrm{C}$ with stirring for 0 to $120 \mathrm{~min}$. The sulfonated PS fibers, or PSNIE, were rinsed with a stepped, increasingly dilute solutions of sulfuric acid until pure deionized water was used, dried and stored in a tightly closed container until further investigation.

\section{Characterization of the fibers}

The morphologies of the PS nanofibers, crosslinked PS fibers and PSNIE were investigated using a scanning electron microscope (SEM, Camscan Mx2000, England). The average diameter of the fibers was determined using image analysis software (JMicroVision V.1.2.7, Switzerland). Their chemical structures were characterized using a Fourier Transform Infrared spectrophotometer (FTIR, Nicolet 4700, USA). 


\section{Determination of crosslinked fibers}

To confirm that the PS nanofibers were crosslinked, the degree of crosslinking (\%) was quantified by determining the amount of fibers that remained in dichloromethane. The crosslinked PS fibers were cut into small fibers and accurately weighed $\left(W_{1}\right)$. The cut fibers were immersed in dichloromethane for $24 \mathrm{~h}$, dried and accurately weighed $\left(\mathrm{W}_{2}\right)$. The percentage of remaining fibers was calculated according to Eq 1.

$$
\text { Remaining fibers }(\%)=\left(\mathrm{W}_{2} / \mathrm{W}_{1}\right) 100 \ldots \text { (1) }
$$

\section{Determination of ion exchange capacity (IEC)}

IEC is a measurement of the number of $\mathrm{H}^{+}$ions per unit mass of the exchange material that can be replaced. The IEC of the PSNIE was performed by the salt splitting titration as previously described [15]. Briefly, the $\mathrm{H}^{+}$sites on the PSNIE were converted into $\mathrm{Na}^{+}$by immersing the PSNIE in $25 \mathrm{ml}$ of $2 \mathrm{~N} \mathrm{NaCl}$ solution for $12 \mathrm{~h}$. The effluent was collected in a flask and measured by titrating to a phenolphthalein endpoint against a $0.01 \mathrm{~N}$ standardized $\mathrm{NaOH}$ solution. The IEC of the PSNIE was calculated according to Eq 2 .

$$
\mathrm{IEC}=\mathrm{cv} / \mathrm{w}
$$

where $c$ is the standardized concentration $(\mathrm{N})$ of $\mathrm{NaOH}$ solution, $\mathrm{v}$ is the volume $(\mathrm{ml})$ of the $\mathrm{NaOH}$ solution at the endpoint and $w$ is the mass $(\mathrm{g})$ of the dried fibers.

\section{Statistical analysis}

All experimental measurements were carried out in triplicate and the data expressed as mean \pm standard deviation (SD). Statistical differences were examined using one-way analysis of variance (ANOVA) followed by least significant difference (LSD) post-hoc tests. The significance level was set at $p<0.05$.

\section{RESULTS}

PS nanofibers with the smallest diameter (376 \pm $36 \mathrm{~nm}$ ) were prepared using our previously described method [13] and were used to prepare the PSNIE. In a preliminary study, PS nanofibers were sulfonated without a prior crosslinking process. The results indicate that PS nanofibers dissolved in $98 \%$ sulfuric acid during the sulfonation process. The dissolution of the PS nanofibers also depended on the sulfonation temperature. An increase in the sulfonation temperature (from 25 to $70{ }^{\circ} \mathrm{C}$ ), resulted in a decrease in the time required for the complete dissolution of PS nanofibers. Therefore, crosslinking of PS nanofibers was important for the preparation of insoluble PSNIE with an acceptable IEC.

The morphology and IEC of the PSNIE were affected by the parameters of the crosslinking (sulfuric acid/formaldehyde ratio, and \% silver sulfate) and sulfonation reaction (time, temperature, and \% silver sulfate) as described in detail below.

\section{Effect of sulfuric acid/formaldehyde ratio on crosslinling}

In this study, formaldehyde was selected as the crosslinking agent and was added into concentrated sulfuric acid at various ratios $(100 / 0,95 / 5,90 / 10,85 / 15,80 / 20$ and 50/50) with $0.1 \% \mathrm{w} / \mathrm{v}$ silver sulfate at $70{ }^{\circ} \mathrm{C}$ for $30 \mathrm{~min}$. Figure 1 shows SEM image, fiber diameter and visual appearance of the PS fibers before and after crosslinking and the PSNIE after sulfonation in $98 \%$ sulfuric acid with $0.2 \% \mathrm{w} / \mathrm{v}$ silver sulfate as the catalyst at $70{ }^{\circ} \mathrm{C}$ for $30 \mathrm{~min}$. The diameter of the crosslinked PS fibers increased from $376 \pm$ $36 \mathrm{~nm}$ (noncrosslinked) to approximately $428 \pm$ 50 to $498 \pm 38 \mathrm{~nm}$, depending on the sulfuric acid/formaldehyde ratio. The visual appearances of the crosslinked PS fibers were similar to the noncrosslinked PS fibers, except the intensity of the yellow color from the formaldehyde decreased. By increasing the amount of formaldehyde (from 5 to 50), the degree of crosslinking was decreased. The highest degree of crosslinking was obtained at the ratio of sulfuric acid/formaldehyde of $95 / 5$. This result was confirmed by the quantification of the remaining fibers in dichloromethane after $24 \mathrm{~h}$ of immersion and a subsequent analysis of the FTIR spectra. Noncrosslinked PS fibers immediately dissolved in dichloromethane. As the portion of formaldehyde increased from 5,10 , 15 and $20 \%$, the percentage of remaining fibers decreased by $95.65,92.31,87.50$ and $80.95 \%$, respectively, and complete dissolution was observed with $50 \%$ formaldehyde.

The FTIR spectra of PS nanofibers, crosslinked PS fibers, and PSNIE are shown in Figure 2. The PS nanofiber's spectrum showed the principal peaks of mono-substituted aromatic hydrocarbon, such as $\mathrm{C}-\mathrm{H}$ stretching at $3025 \mathrm{~cm}^{-1}$; overtone and combination bands at 1939, The spectra of crosslinked PS fibers showed new peaks caused by the sulfone crosslinkages, namely an asymmetric stretching vibration at $1306 \mathrm{~cm}^{-1}$ and a symmetric stretching vibration at $1091 \mathrm{~cm}^{-1}$. These FTIR spectra indicate that the PS nanofibers were crosslinked with the sulfone crosslinkage. The IEC of the crosslinked PS 


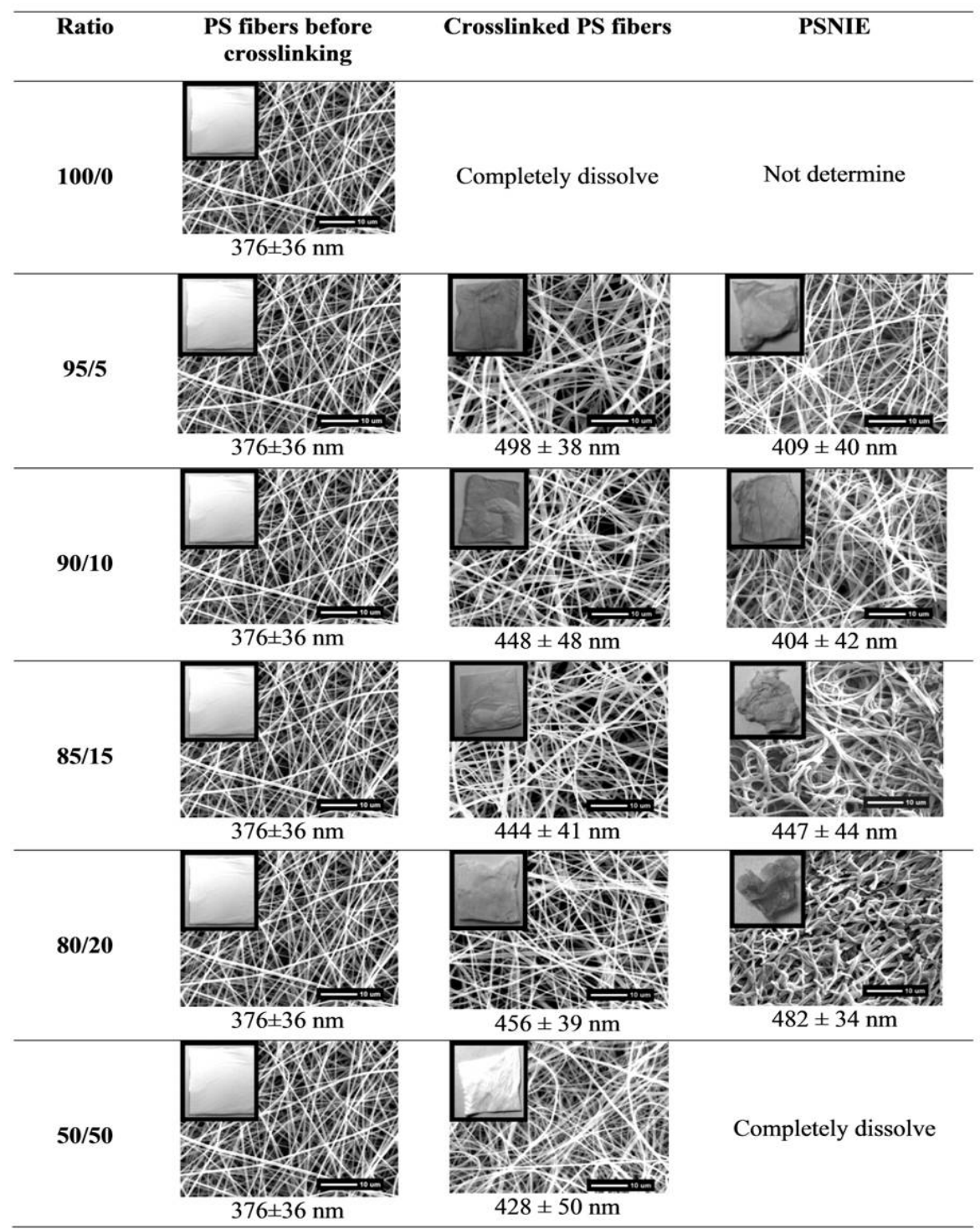

Figure 1: Scanning electron micrographs $(1000 \mathrm{x})$, visual appearance and diameter of PS fibers (prior to crosslinking), crosslinked PS fibers and PSNIE at various sulfuric acid/formaldehyde ratios

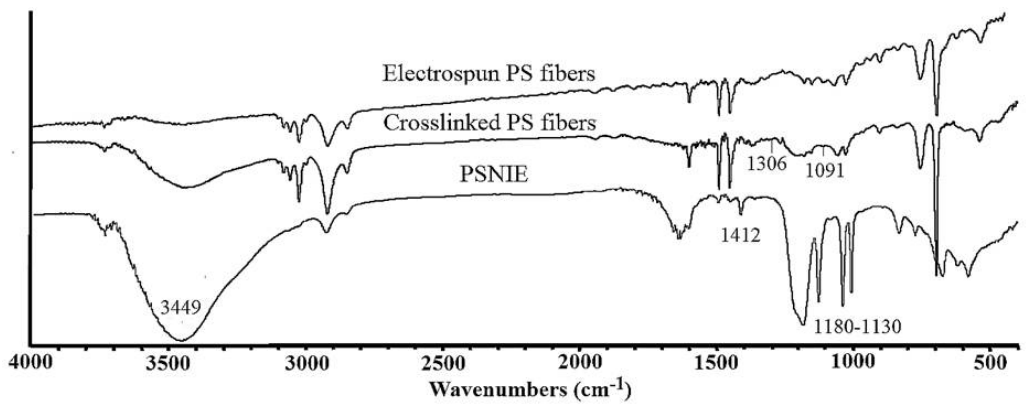

Figure 2: FTIR spectra of the electrospun PS fibers, crosslinked PS fibers (90/10 sulfuric/formaldehyde ratio, 0.1 $\%$ silver sulfate, $30 \mathrm{~min}, 70^{\circ} \mathrm{C}$ ) and PSNIE (sulfonation, $30 \mathrm{~min}, 70^{\circ} \mathrm{C}$ )

fibers was approximately $0 \mathrm{meq} / \mathrm{g}$-dry-fiber for all sulfuric acid/formaldehyde ratios. A possible structure from the crosslinked PS fibers after the crosslinking reaction is shown in Figure 3.
From the FTIR spectrum, new peaks were observed from aromatic sulfonic acid (R-SO2$\mathrm{OH})$, namely, asymmetric stretching and symmetric stretching of $(\mathrm{O}=\mathrm{S}=\mathrm{O})$ at 1188 and $1130 \mathrm{~cm}^{-1}$, respectively; S-O at $670 \mathrm{~cm}^{-1}$; and O$\mathrm{H}$ at $3449 \mathrm{~cm}^{-1}$ (Figure 2). Additional peaks from 
para-substituted aromatic hydrocarbons, namely, overtone and combination peaks at 2000-1800 $\mathrm{cm}^{-1}$ and a substitution bands from $\mathrm{C}-\mathrm{H}$ vibrations ( $p$ ) at $835.7 \mathrm{~cm}^{-1}$, were also observed. These peaks indicate that sulfonic acid groups reacted with the aromatic hydrocarbons of the PS nanofibers at the para-position $[13,16]$. In addition, a peak caused by $\mathrm{C}-\mathrm{H}$ vibration at 1412 $\mathrm{cm}^{-1}$ was found, which was probably due to a methylene bridge in the para-position [17]. A possible structure for the PSNIE after the sulfonation reaction was shown in Figure 3.

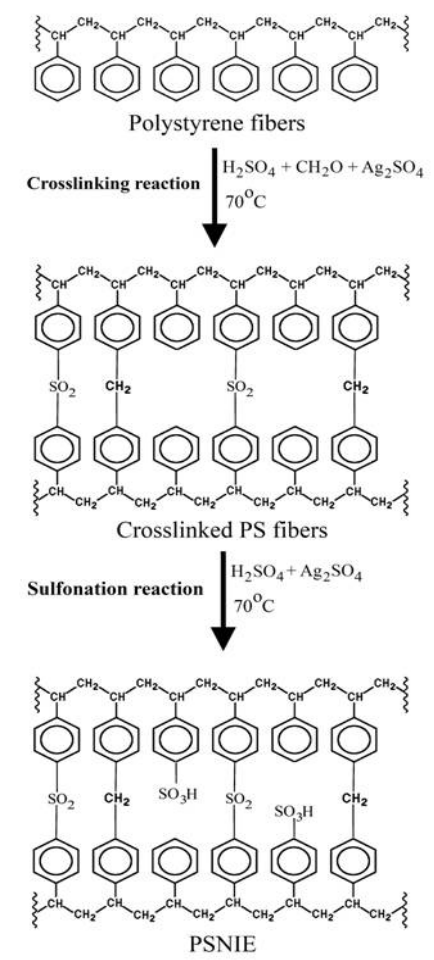

Figure 3: The crosslinking and sulfonation reaction of PS fibers

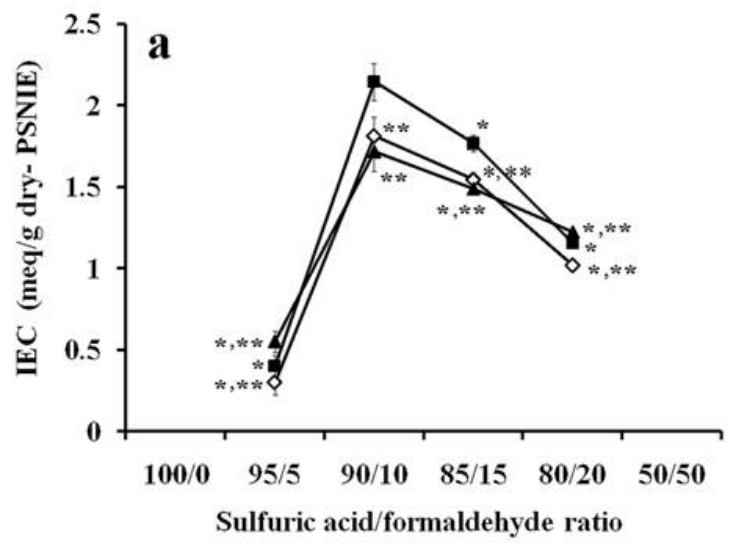

The effect of the sulfuric acid/formaldehyde ratio on IEC is shown in Figure 4a. The IEC of the PSNIE increased as the sulfuric acid/formaldehyde ratio increased and peaked at a ratio of 90/10 (2.14 meq/g-dry-PSNIE). When the sulfuric acid/formaldehyde ratio increased from $95 / 5$ to $90 / 10$, the IEC increased from 0.61 to $2.14 \mathrm{meq} / \mathrm{g}$-dry-PSNIE. At the ratio of $85 / 15$ and $80 / 20$, IEC did not increase. This result indicates that the optimal ratio of sulfuric acid/formaldehyde for crosslinking the PS nanofibers was at 90/10. The large amount of remianing fibers derived from the ratio of $90 / 10$ after immersion in dichloromethane supports the claim that the above conditions were optimal. At the ratio of 50/50, IEC could not be determined.

\section{Effect of silver sulfate on crosslinking}

In this study, the PS nanofibers were crosslinked a sulfuric acid/formaldehyde ratio of 100/0, 95/5, $90 / 10,85 / 15,80 / 20$ and 50/50, while the amount of silver sulfate varied among $0,0.1$ and 0.2 $\% \mathrm{w} / \mathrm{v}$. The crosslinking time was $5-75 \mathrm{~min}$ at 70 ${ }^{\circ} \mathrm{C}$. Then the crosslinked fibers were sulfonated in $98 \%$ sulfuric acid with $0.2 \% \mathrm{w} / \mathrm{v}$ silver sulfate as the catalyst at $70^{\circ} \mathrm{C}$ for 30 min to obtain the PSNIE. Figure 4a shows the effect of the amount of silver sulfate in various sulfuric acid/formaldehyde ratios on the IEC of the PSNIE. The sulfuric acid/formaldehyde ratio of $90 / 10$ with $0.1 \% \mathrm{w} / \mathrm{v}$ silver sulfate resulted in the highest IEC value of $2.14 \mathrm{meq} / \mathrm{g}$-dry-PSNIE. Figure $4 \mathrm{~b}$ shows the effect of the amount of silver sulfate at various crosslinking times on the IEC of the PSNIE. The highest IEC value, $2.86 \mathrm{meq} / \mathrm{g}$ dry-PSNIE, was observed at $10 \mathrm{~min}$ of crosslinking with $0.1 \% \mathrm{w} / \mathrm{v}$ silver sulfate.

Figure 4: Effect of the percent of silver sulfate $((\diamond) 0 \%,(\boldsymbol{\square}) 0.1 \%$ and $(\boldsymbol{A}) 0.2 \%)$ on ion exchange capacity (IEC) of PSNIE (a) at various sulfuric acid/formaldehyde ratio and (b) crosslinking time. Each point represents the mean of three experiments; *indicates significant differences $(p<0.05)$ of sulfuric acid/formaldehyde ratio and crosslinking time compared with $90 / 10$ and 10 min, respectively; ${ }^{* *}$ indicates significant differences $(p<0.05)$ of percent of silver sulfate compared with $0.1 \%$.

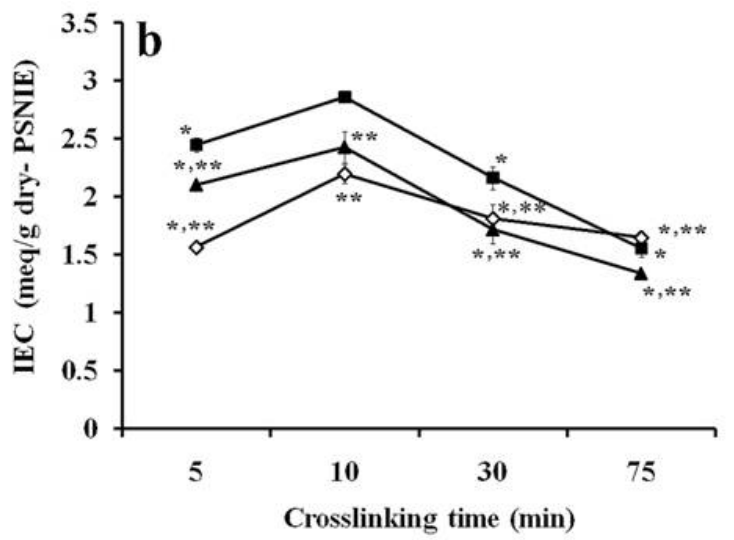




\section{Effect of silver sulfate on sulfonation reaction}

In this study, the crosslinked PS fibers used in the sulfonation reaction were obtained under the following crosslinking reaction conditions: a sulfuric acid/formaldehyde ratio of 90/10 was used with $0.1 \%$ silver sulfate at $70{ }^{\circ} \mathrm{C}$ for $10 \mathrm{~min}$. The conditions for the sulfonation reaction were $98 \%$ sulfuric acid with $0-1 \% \mathrm{w} / \mathrm{v}$ silver sulfate as the catalyst at $70{ }^{\circ} \mathrm{C}$ for $30 \mathrm{~min}$. The highest IEC value, $2.86 \mathrm{meq} / \mathrm{g}$-dry-PSNIE, was observed at $0.2 \% \mathrm{w} / \mathrm{v}$ silver sulfate. At the higher percentage of silver sulfate $(0.3-1.0$ $\% \mathrm{w} / \mathrm{v})$, the IEC of the PSNIE decreased to 2.55 $2.71 \mathrm{meq} / \mathrm{g}$-dry-PSNIE. This result indicated that the optimal amount of silver sulfate $(0.2 \% \mathrm{w} / \mathrm{v})$ as the catalyst of the sulfonation reaction results in an increase in the IEC value.

\section{Effect of sulfonation time and temperature on sulfonation reaction}

In this study, the crosslinked PS fibers used in the sulfonation reaction were obtained under the following crosslinking reaction conditions: a sulfuric acid/formaldehyde ratio of $90 / 10$ was used with $0.1 \%$ silver sulfate at $70{ }^{\circ} \mathrm{C}$ for $10 \mathrm{~min}$. The sulfonation reaction conditions varied time and temperature from 0 to $120 \mathrm{~min}$ and $50-100$ ${ }^{\circ} \mathrm{C}$, respectively. Figure 5 reveals that the IEC of PSNIE increased with sulfonation time and temperature. The IEC increased with sulfonation

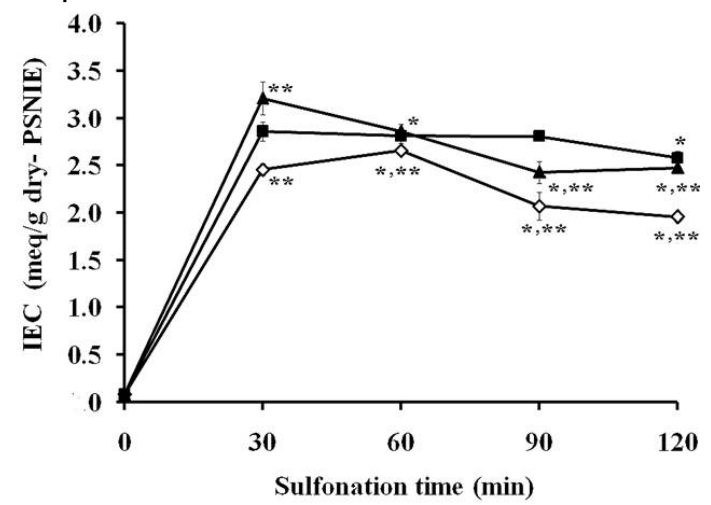

Figure 5: Effect of sulfonation time and temperature $\left((\diamond) 50^{\circ} \mathrm{C},(\boldsymbol{\bullet}) 70^{\circ} \mathrm{C}\right.$ and $\left.(\boldsymbol{\Delta}) 100^{\circ} \mathrm{C}\right)$ on ion exchange capacity (IEC) of polystyrene nanofiber ion exchangers (PSNIE). Each point represents the mean of three experiments; * indicates significant differences $(p<0.05)$ of sulfonation time compared with $30 \mathrm{~min}$; ** indicates significant differences $(p<0.05)$ of sulfonation temperature compared with $70{ }^{\circ} \mathrm{C}$.

time, which the IEC peaked at approximately 30 $\min$. For sulfonation temperatures of 50,70 and $100{ }^{\circ} \mathrm{C}$, the IEC of the PSNIE was 2.46, 2.86 and $3.21 \mathrm{meq} / \mathrm{g}$-dry-PSNIE, respectively. However, the IEC decreased at the longer sulfonation times because of the shrinkage and dissolution of the PSNIE. The maximum IEC of the PSNIE was $3.21 \mathrm{meq} / \mathrm{g}$-dry-PSNIE at $100{ }^{\circ} \mathrm{C}$ for $30 \mathrm{~min}$ of sulfonation time.

\section{DISCUSSION}

PS nanofibers could not produce PSNIE via sulfonation because PS nanofibers were dissolved in sulfuric acid. One possible reason is that sulfonic acid groups may have attached to the surface of the PS nanofibers, causing increase in the ionization and dissolution of the PS nanofibers. This result was consistent with a previous work [13] which reported that the noncrosslinked PS nanofibers were soluble at high degrees of sulfonation. Therefore, crosslinking the PS nanofibers are necessary for the preparation of insoluble PSNIE with an acceptable IEC. PS nanofibers were successfully crosslinked with sulfuric acid/formaldehyde without sulfonation reaction, although sulfuric acid was in the crosslinking agent because the presence of aromatic sulfonic acid peaks at 1200 - $1100 \mathrm{~cm}^{-1}$ would indicate that sulfonation occurred; however, the peaks were not observed in the spectra of crosslinked PS fibers (Figure 2) and the IEC of the crosslinked PS fibers were 0 meq/g-dry-fiber which indicate that sulfonic acid groups were absent in the crosslinked PS fibers during the crosslinking reaction. The crosslinking agent (i.e., formaldehyde) possibly introduced methylene bridges, in addition to sulfone bridges, into the PS fibers. However, $\mathrm{C}-\mathrm{H}$ vibration at $1412 \mathrm{~cm}^{-1}$ (methylene bridge) was not observed in the FTIR spectra of the crosslinked PS fibers because the methylene bridge overlapped with $\mathrm{C}-\mathrm{H}$ deformations from aliphatic hydrocarbon at $1450-1400 \mathrm{~cm}^{-1}$.

Increased crosslinking of PS nanofibers caused the IEC of PSNIE to decrease (Figure 4). This result is similar to the capacity of polystyrene/divinylbenzene ion exchange fibers which decreased as the degree of crosslinking increases [18]. IEC of PSNIE was lowest at the sulfuric acid/formaldehyde of 95/5. This might be due to the fact that the highest crosslinking of PS nanofibers was hindered the diffusion of sulfonic acid that would interact with the crosslinked PS nanofibers. Decrease in crosslinked PS nanofibers at the ratio of $80 / 20$ did not cause IEC to increase. This might be due to shrinkage, closer proximity, and additional breaks of the PSNIE at this ratio as compared with the other ratios (Figure 1), which resulted in the lowest IEC. These observations were consistent with a previous study, which revealed that a decrease in IEC is due to the shrinkage and dissolution of the fibers during sulfonation reaction [13]. PS nanofibers were insufficiently crosslinked at a ratio of $50 / 50$, to completely dissolve during the 
sulfonation reaction. Furthermore, in our previous study, IEC decreased when crosslinking time was increased [19].

Increase in sulfonation temperature caused IEC of PSNIE to increase because faster sulfonation occurred. These results are consistent with a previous study that used a sulfonation time of 4 $\mathrm{h}$, which resulted in the IEC of cation exchange fibers to increase from 1.30 to $4.50 \mathrm{meq} / \mathrm{g}$-dryfibers when the temperature of sulfonation was increased from 25 to $95{ }^{\circ} \mathrm{C}$ [20]. It was observed that higher temperatures increased the rate of sulfonation reaction [18]. However, the IEC of PSNIE decreased with increase in sulfonation time which might be due to the shrinkage and dissolution of the PSNIE.

\section{CONCLUSION}

PSNIE were successfully prepared by electrospinning, subsequent crosslinking with sulfuric acid/formaldehyde and sulfonation in sulfuric acid, which induced cation exchange functionality on the fiber's surface. The PSNIE prepared from crosslinked PS nanofibers in a sulfuric acid/formaldehyde ratio of $90 / 10$ with 0.1 $\%$ silver sulfate for $10 \mathrm{~min}$ at $70{ }^{\circ} \mathrm{C}$, followed by sulfonation in sulfuric acid with $0.2 \%$ silver sulfate for $30 \mathrm{~min}$ at $100{ }^{\circ} \mathrm{C}$ exhibited maximum IEC of $3.21 \mathrm{meq} / \mathrm{g}$-dry-PSNIE. Cationic drugs can be loaded into this PSNIE by electrostatic interactions for both topical and oral controlledrelease delivery.

\section{ACKNOWLEDGEMENT}

The authors would like to thank the Commission of Higher Education (Thailand), the Thailand Research Funds through the Golden Jubilee Ph.D. Program (Grant no. PHD/0005/2552) and the Silpakorn University Research and Development Institute for financial support (Grant no. SURDI 55/02/2555).

\section{REFERENCES}

1. Anand V, Kandarapu R, Garg S. Ion-exchange resins: carrying drug delivery forward. Drug Discov Today 2001; 6: 905-914.

2. Merino SM, Carrera A, Monte E, Jimenez-Torres NV. Adsorption of methotrexate and calcium leucovorin onto cholestyramine in vitro. Int J Pharm 2004, 278: 283-291.

3. Scott TR, Graham SM, Schweitzer EJ, Bartlett ST. Colonic necrosis following sodium polystyrene sulfonate (Kayexalate ${ }^{\circledR}$ )-sorbitol enema in a renal transplant patient. Dis Colon Rectum 1993; 36: 607-609.

4. Jaskari $T$, Vuorio $M$, Kontturi KS, Urtti $A$, Manzanares $J A$, Hirvonen J. Controlled transdermal iontophoresis by ion-exchange fiber. J Controlled Release 2000; 67:179-190.

5. Yu L, Li S, Yuan Y, Dai Y, Liu H. The delivery of ketoprofen from a system containing ion-exchange fibers. Int J Pharm 2006; 319: 107-113.

6. Yao $H, X u L$, Han F, Che X, Dong Y, Wei M, Guan J, Shi $X, L i$ S. A novel riboflavin gastromucoadhesive delivery system based on ionexchange fiber. Int J Pharm 2008; 364: 21-26.

7. Kankkunen T, Huupponen I, Lahtinen K, Sundell M, Ekman K, Kontturi KS, Hirvonen J. Improved stability and release control of levodopa and metaraminol using ion-exchange fibers and transdermal iontophoresis. Eur J Pharm Sci 2002; 16: 273-280.

8. Yu L, Li S, Yuan Y, Dai Y, Liu H. The delivery of ketoprofen from a system containing ion-exchange fibers. Int J Pharm 2006; 319: 107-113.

9. An $H$, Shin $C$, Chase GG. Ion exchanger using electrospun polystyrene nanofibers. J Membr Sci 2006; 283: 84-87.

10. Aussawasathien D, Sahasithiwat S, Menbangpung $L$. Electrospun camphorsulfonic acid doped poly(otoluidine)-polystyrene composite fibers: Chemical vapor sensing. Synth Met 2008; 158:259-263.

11. Yoshioka T. Studies of polystyrene-based ion-exchange fiber. III. A novel fiber-form chelating exchanger and its adsorption properties for heavy-metal ions. Bull Chem Soc Jpn 1985; 58: 2618-2625.

12. Baker SC, Southgate J. Towards control of smooth muscle cell differentiation in synthetic $3 D$ scaffolds. Biomaterials 2008; 29: 3357-3366.

13. Nitanan $T$, Opanasopit $P$, Akkaramongkolporn $P$, Rojanarata T, Ngawhirunpat T, Supaphol P. Effects of processing parameters on morphology of electrospun polystyrene nanofibers. Korean $\mathrm{J}$ Chem Eng 2012; 29: 173-181.

14. Tillet $G$, Boutevin B, Ameduri B. Chemical reactions of polymer crosslinking and post-crosslinking at room and medium temperature. Prog Polym Sci 2011; 36: 191-217.

15. Akkaramongkolporn $P$, Ngawhirunpat $T$, Opanasopit $P$. Preparation and evaluation of differently sulfonated styrene-divinylbenzene cross-linked copolymer cationic exchange resins as novel carriers for drug delivery. AAPS Pharm Sci Tech 2009; 10: 641-648.

16. Gunzler $H$, Gremlich HU, IR Spectroscopy An Introduction. Weinheim: Wiley-VCH; 2002; pp 361.

17. Manfredi LB, Osa O, Galego GF, Vazquez A. Structureproperties relationship for resols with different formaldehyde/phenol molar ratio. Polymer 1999; 40: 3867-3875

18. Dominguez L, Benak KR, Economy J. Design of high efficiency polymeric cation exchange fibers. Polym Adv Technol 2001; 12: 197-205.

19. Nitanan $T$, Akkaramongkolporn $P$, Rojanarata $T$, Ngawhirunpa $T$, Opanasopit $P$. Effect of crosslinking time on ion exchange capacity of polystyrene nanofiber ion exchanges. Adv Materials Res 2012; 506: 437-440.

20. Economy J, Dominguez L, Mangun CL. Polymeric ionexchange fibers. Ind Eng Chem Res 2002; 41: 6436-6442. 